\title{
Transfusion Dependent Homozygous $\alpha$-Thalassemia in Patients Associated with Hypospadias in Three Survivors
}

Syahzuwan Hassan ${ }^{1}$, Rahimah Ahmad ${ }^{1 *}$, Faidatul Syazlin Abdul Hamid ${ }^{1}$, Nur Aisyah Aziz ${ }^{1}$, Syahira Lazira Omar ${ }^{1}$, Siti Hida Hajira Mohamad Arif ${ }^{1}$, Aini Salmah Rabiee $^{2}$, Yeoh Seoh Leng ${ }^{3}$, Mohd Hishamshah Mohd Ibrahim ${ }^{4}$ and Zubaidah Zakaria ${ }^{1}$

${ }^{1}$ Haematology Unit, Institute for Medical Research, Jalan Pahang, 50588 Kuala Lumpur, Malaysia

${ }^{2}$ Hospital Bintulu, Jalan Nyabau, 97000 Bintulu, Sarawak, Malaysia

3 Jabatan Pediatrik, Hospital Pulau Pinang, Jalan Residensi, 10990 Georgetown, Pulau Pinang, Malaysia

${ }^{4}$ Institut Pediatrik Hospital Kuala Lumpur, Jalan Pahang, 50586 Kuala Lumpur, Malaysia

*Corresponding author: Rahimah Ahmad, Hematology Unit, Institute for Medical Research, Jalan Pahang, 50588 Kuala Lumpur, Malaysia, Tel: +603-2616-2666; Fax: +603-2693-9335; E-mail: rahimah@imr.gov.my

Received date: Nov 24, 2014, Accepted date: Jan 23, 2015, Publication date: Jan 30, 2015

Copyright: @ 2015 Hassan S, et al. This is an open-access article distributed under the terms of the Creative Commons Attribution License, which permits unrestricted use, distribution, and reproduction in any medium, provided the original author and source are credited.

\begin{abstract}
Alpha-thalassemia results from a dysfunction of the $\alpha$-globin gene. Types of mutations include large deletions and point mutations. The most severe form of a-thalassemia is hydrops fetalis, which is caused by homozygosity of certain types of either deletion or point mutations, and some cases were the results of a combination of both. Here, we describe three cases of homozygous $\alpha$-thalassemia who continue to survive, all with hypospadias. The first two cases were 5-year-old twins that were diagnosed with homozygous SEA deletion and the first description of a 20month-old child with the genotype of the homozygous $\mathrm{Cd} 59$ (GGC>GAC) mutation of the HBA2 gene. Prognoses for any a-thalassemia mutation types that are known to lead to hydrops fetalis in male fetuses should be informed about the potential survival associated with hypospadias.
\end{abstract}

Keywords: Homozygous a2 Cd 59 (GGC>GAC); Homozygous SEA deletion; $\alpha$-thalassaemia major; Hypospadias

\section{Introduction}

Alpha-thalassemia disorders are a group of hereditary anemias leading to variable disease severity. The least extreme are asymptomatic due to one or two of four dysfunctional a-globin genes. The most severe form is Hemoglobin ( $\mathrm{Hb})$ Bart's hydrops fetalis, where the deletion of all four a-globin genes usually leads to severe anemia with resulting hypoxia, heart failure, and fatal $\alpha$-thalassemia disease either in-utero or at stillbirth. Initial laboratory testing includes mean corpuscular volume (MCV) and mean corpuscular hemoglobin $(\mathrm{MCH})$ determination, as well as a quantitative assessment of the $\mathrm{HbA} 2$ and $\mathrm{HbF}$. Carrier screening is difficult due to unchanged HbA2 and $\mathrm{HbF}$ in their hypochromic microcytic red blood cells (RBCs), whereas $\mathrm{Hb}$ Bart and $\mathrm{Hb} \mathrm{H}$ are detectable by $\mathrm{Hb}$ electrophoresis. Genotyping known deletions and point mutations of $\alpha$-thalassemia can be achieved by amplification refractory mutation system (ARMS) and Gap-Polymerase Chain Reaction (Gap-PCR).

Due to severe ineffective erythropoiesis, hydropic fetuses have massive organomegaly, severe albuminemia, heart failure, body edema, growth failure, and intrauterine demise [1]. High incidences of congenital abnormalities, such as limb defects, hydrocephalus, microcephaly, atrial septal defects, pulmonary hypoplasia, hypospadias, and skeletal dysplasia, have also been reported [2]. Survival with $\mathrm{Hb}$ Bart's hydrops fetalis is possible following premature delivery and treatment with post-delivery transfusions [3] or intrauterine umbilical vein transfusions (IUT) [4]. A blood transfusion with iron chelator provides symptom relief, whereas allogeneic stem cell transplantation [5] is the only curative therapy for thalassemia.
Recently, an in-utero hematopoietic cell transplantation (IUHCT) was attempted [6].

The intermediate form is $\mathrm{Hb} \mathrm{H}$, where three $\alpha$-globin genes are affected by deletions or by compound heterozygous point mutations. $\mathrm{Hb} \mathrm{H}$ resulting from a combination of a deletion and a point mutation may have a more severe phenotype than most three-deletional $\alpha$ thalassemia [7]. Clinically, they are characterized by moderate to severe microcytic, hypochromic, hemolytic anemia, mild jaundice, and moderate hepatosplenomegaly [8]. Hb $\mathrm{H}$ may also lead to hydrops fetalis, as presented in a case report by Lorey et al. [9] in a fetus with Cd 35 (TCC>CCC) and $\alpha$-Filipino deletion [9], as well as in a patient that inherited Mediterranean deletion compounded with aTSaudi (polyA AATAAA $>$ AATAAG) [10]. A more severe outcome was further evident in point mutations of $\alpha$-thalassemia in a case report by Naiggolan et al. (2010) where hydrops fetalis resulted from the homozygous point mutation $\mathrm{Cd} 59$ (GGC>GAC) [11]. Here, we present cases of surviving children born with hypospadias, one with the same genotype of homozygous Cd 59 (GGC>GAC) and twin siblings homozygous for SEA deletions. They are transfusiondependent and are managed as thalassemia major patients.

Hypospadias is a congenital malformation in which the urethral opening is displaced along the ventral side of the penis. It is classified into anterior, middle, and posterior hypospadias based on the location of the urethral meatus [12]. The etiology of hypospadias is multifactorial, involving both genes and environmental factors [13]. Different molecular factors have been identified as being associated with syndrome-associated and isolated hypospadias cases. For instance, the homeobox gene A13 (HOXA13) in knockout mice caused hypospadias [14]. The mutation HOXA13 in hand foot-genital syndrome frequently presented with hypospadias [15]; however, no sequence variant was found in hypospadias patients without the 
syndrome [16]. Genetic studies have found many candidate genes associated with hypospadias; however, only variants in the $\mathrm{X}$ chromosomal gene DGKK encoding diacylglycerol kinase $\kappa$ were consistently associated with anterior and middle forms of hypospadias [17-19]. Hypospadias was also reported in male infants with homozygous SEA deletions. It was speculated that the deletion might either generate a gene product arising from the deletion's breakpoint on the chromosome $16 \mathrm{p} 13.3$ or create an imbalance transcription on the -14 gene harboring the HS40 promoter of the a-globin [20]. However, no cryptic mRNA and potential exons were found around the deletion breakpoint, and a comparable amount of transcription was found in the -14 gene of SEA deletion/hypospadias survivor cDNAs [21].

\section{Case Report}

\section{Case 1}

These patients are twin sibling, mentally normal boys. They presented with severe anemia at birth, and they were prematurely delivered at 34 weeks gestation. The first child (twin 1) had a failure to thrive, while the second child (twin 2) had poor growth. Both had organomegaly, requiring monthly blood transfusions, and they were noted to have penoscrotal hypospadias. No pre-transfusion indices were available for either of them. A full blood film of twin 1 showed anisopoikilocytosis and hypochromic RBCs. Many nucleated RBCs, microspherocytes, spherocytes, schistocytes, and polychromatic cells were observed. Occasionally, myelocytes and atypical lymphocytes were seen. In twin 2 , the presence of poikilocytosis, hypochromic cells, microcytes, target cells, and nucleated RBCs were seen. Occasional Howell-Jolly bodies and myelocytes were also observed. DNA analysis revealed both parents as carriers of the common SEA deletion, and the twins were both homozygous for SEA deletions.

\section{Case 2}

The infant boy was born to a woman of Iban descent, gravida 2, para 1. At term, she had high blood pressure and she underwent a caesarean section for impending eclampsia. During earlier antenatal examinations, her blood pressure was normotensive, and she did not have polyhdramnios or any history of antepartum hemorrhage. The proband was delivered with a weight of $1.68 \mathrm{~kg}$ at 35 weeks gestation. $\mathrm{His} \mathrm{Hb}$ at birth was $7.1 \mathrm{~g} / \mathrm{dL}$, and thrombocytopenia was seen. Upon abdominal examination, hepatosplenomegaly was seen. Peripheral blood film revealed anisopoikilocytosis with marked hypochromic, macro, and microcytic cells. Moderate polychromasia was seen with some teardrop, bite, pencil shape, and target cells observed. He was immediately transfused after birth with a subsequent transfusion 9 days later. He was also found to have hypospadias without other abnormalities. Since birth, repeated blood transfusions were given and his recent full blood count showed a retic count of $8 \%$, and $\mathrm{H}$ inclusion was not observed. At birth, his enlarged liver and spleen were $6 \mathrm{~cm}$ and $5 \mathrm{~cm}$ below the costal margins, respectively. His recent examination showed his liver and spleen had shrunk to $2 \mathrm{~cm}$ and $3 \mathrm{~cm}$ below costal margins, respectively. $\mathrm{Hb}$ electrophoresis was not performed at birth, his parents were investigated for any hemoglobinopathies with FBC, and a hemoglobin analysis was performed.

A molecular analysis of DNA sequencing confirmed both parents as carriers of the a2-globin gene Cd 59 (GGC>GAC) and the index homozygous for $\mathrm{Cd} 59$ (GGC>GAC) (Figure 1). An $\mathrm{FBC}$ and hemoglobin typing analysis of the referred blood samples are shown in Table 1.

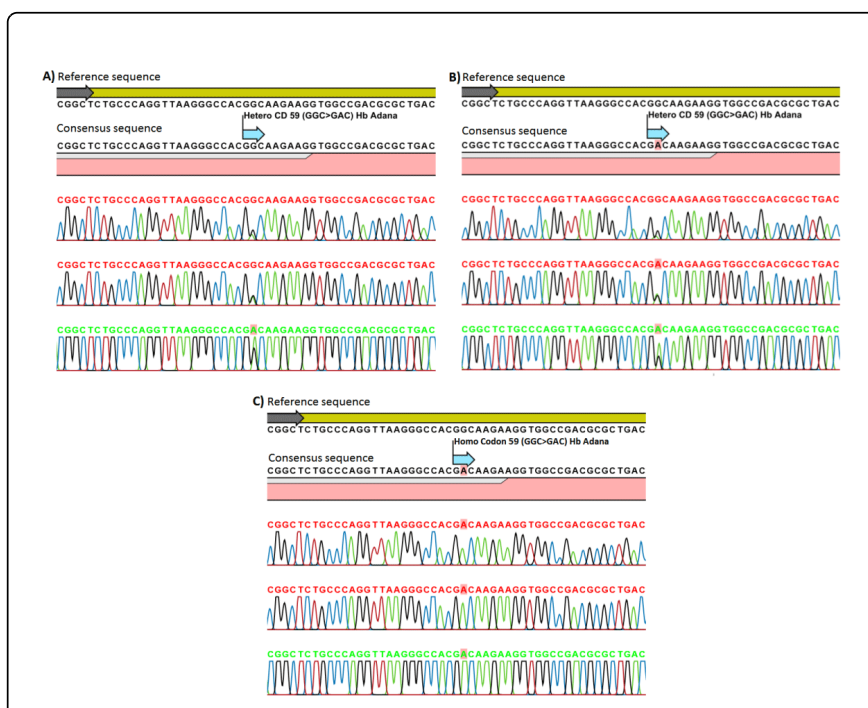

Figure 1: DNA sequencing results showing mutations of: (A) the father trait for Cd 59 (GGC>GAC); (B) the mother trait for Cd 59 (GGC>GAC); and (C) the proband with homozygous $\mathrm{Cd} 59$ $(\mathrm{GGC}>\mathrm{GAC})$.

\begin{tabular}{|l|l|l|l|}
\hline Parameters & Patient $^{*}$ & Mother & Father \\
\hline Age (year)/sex & 1 Y10M/M & $31 / \mathrm{F}$ & $36 / \mathrm{M}$ \\
\hline Hb (g/dL) & 7.1 & 14.3 & 15.1 \\
\hline RBC (106/pL) & 3.84 & 5.18 & 5.6 \\
\hline MCV (fL) & 78.9 & 82.8 & 80.2 \\
\hline MCH (pg) & 21.5 & 27.6 & 27.0 \\
\hline MCHC (g/dL) & 27.1 & 33.3 & 33.6 \\
\hline RDW-CV (\%) & NA & NA & NA \\
\hline HbA (\%) & 76.7 & 86.9 & 85.7 \\
\hline HbA 2 (\%) & 2.0 & 2.6 & 2.8 \\
\hline HbF (\%) & 10.3 & 1.4 & 1.3 \\
\hline
\end{tabular}

Table 1: Hematological parameters and molecular analysis. NA- not available; ${ }^{*}$ Post-transfusion.

\section{Discussion}

Homozygous SEA deletion and the a2-globin gene Cd 59 (GGC>GAC) are among several $\alpha$-thalassemia mutation types that cause hydrops fetalis, though the frequencies of homozygous SEA deletions are much higher due to high SEA deletion carriers among Asians. Many cases of non-hydropic newborns have been previously reported, and the most striking associations were hypospadias among the surviving male newborns with known $\alpha$-thalassemia mutations. The first case was reported in 1985 by Beaudry and his team in a boy of Chinese-descent; however, the exact mutation on the a-globin gene 
could not be confirmed due to the lack of DNA analyses. To date, 10 cases of non-hydrops male newborns with homozygous SEA deletions associated with genitalia defects have been reported [22-25]; however, none have been reported involving homozygous Cd 59 (GGC>GAC).

$\mathrm{Hb}$ Adana (Cd 59, GGC>GAC) was first encountered in the a1globin gene in Turkish patients [26]. Subsequently, the same nucleotide substitution was found in the a2-globin gene (HBA2) in an Albanian patient [27]. It was also reported that compound heterozygous a1-globin gene Cd 59 (GGC>GAC) with $\alpha^{\circ}$ thalassemia-1 deletion leads to severe hemolytic anemia requiring regular blood transfusions [26].

Homozygous a2-globin Cd 59 (GGC>GAC) was also found to manifest hydrops fetalis [11], thus prompting an extensive molecular diagnosis of mutations within $\alpha$-, and the $\beta$-globin gene which may have ameliorated the clinical outcome of the patient case 2. Our extensive tests involved PCR amplification of multiplex amplification refractory mutation system (MARMS), multiplex Gap-PCR, multiplex ligation-dependent probe amplification (MLPA), sequencing of the $\alpha$ and $\beta$-globin point mutations and deletions, and $\alpha$-triplication tests. We did not detect any $\beta$-thalassemia mutations, deletions, or $\alpha$ triplication. Then, we were informed by the pediatrician of his accompanying hypospadias. To our knowledge, this is the first report of $\mathrm{Hb}$ Adana associated with hypospadias.

Hypospadias was possibly induced in utero, and/or the edema secondary to hydrops fetalis could have led to a failure of the normal fusion of the urogenital folds. Hypospadias could also possibly be due to a defect of another gene located at the chromosome 16p13.3 region [24]. Genetically, syndrome-associated hypospadias could probably be due to the different mutations in a single gene that can cause different phenotypes due to unknown genetic factors involved in genital determination and/or due to a differentiation located in an altered chromosomal location due to inversion, deletion, or insertion mutations [28]. However, homozygous Cd 59 (GGC>GAC) is a point mutation (base substitution) not involved in the fusion of an altered gene at the chromosome 16p13.3.

The variable outcomes of the same mutation types show the complex factor influencing disease severity. The predictive outcomes of $\alpha$-thalassemia based on mutation types are not always straightforward; thus, it complicates genetic counselling. Prenatal care for the fetus for homozygous $\alpha$-thalassemia leading to hydrops fetalis must also include an examination of genital formation. Parent carriers of SEA deletion and a2-globin Cd 59 (GGC>GAC) should be informed of the possible survival of their fetus if hypospadias is observed.

\section{Conclusions}

We report our cases of non-hydropic homozygous a-thalassemia SEA deletions, as well as the first case of homozygous a2-globin Cd 59 (GGC>GAC), leading to transfusion-dependent $\alpha$-thalassemia major that occurred in Chinese twin boys and an Iban ethnic boy, respectively. This case provides valuable information regarding the clinical manifestations of such genotypes when associated with hypospadias.

\section{Acknowledgments}

The authors would like to thank Director General of Health for the permission to publish this case report. We would also like to thank the
National Prevention and Control Program for Thalassemia Fund for supporting our efforts.

\section{References}

1. Vichinsky EP (2009) Alpha thalassemia major--new mutations, intrauterine management, and outcomes. Hematology Am Soc Hematol Educ Program .

2. Liang ST, Wong VC, So WW, Ma HK, Chan V, et al. (1985) Homozygous alpha-thalassaemia: clinical presentation, diagnosis and management. A review of 46 cases. Br J Obstet Gynaecol 92: 680-684.

3. Bianchi DW, Beyer EC, Stark AR, Saffan D, Sachs BP, et al. (1986) Normal long-term survival with alpha-thalassemia. J Pediatr 108: 716-718.

4. Carr S, Rubin L, Dixon D, Star J, Dailey J (1995) Intrauterine therapy for homozygous alpha-thalassemia. Obstet Gynecol 85: 876-879.

5. Thomas ED, Buckner CD, Sanders JE, Papayannopoulou T, BorgnaPignatti C, et al. (1982) Marrow transplantation for thalassaemia. Lancet 2: 227-229.

6. Derderian SC, Jeanty C, Walters MC, Vichinsky E, Mackenzie TC (2015) In utero hematopoietic cell transplantation for hemoglobinopathies. Front. Pharmacol 5: 1-4.

7. Vichinsky EP (2005) Changing patterns of thalassemia worldwide. Ann N Y Acad Sci 1054: 18-24.

8. Galanello R, Cao A (2011) Gene test review. Alpha-thalassemia. Genet Med 13: 83-88.

9. Lorey F, Charoenkwan P, Witkowska HE, Lafferty J, Patterson M, et al. (2001) Hb H hydrops foetalis syndrome: a case report and review of literature. Br J Haematol 115: 72-78.

10. Viprakasit V, Green S, Height S, Ayyub H, Higgs DR (2002) Hb H hydrop fetalis syndrome associated with the interaction of two common determinants of $\hat{\mathrm{I}} \pm$ thalassaemia (--MED/ $\hat{\mathrm{I}} \pm \mathrm{TS}$ Saudi $\hat{\mathrm{I}} \pm$ ). British Journal of Haematology 117: 759-762.

11. Nainggolan IM, Harahap A, Setianingsih I (2010) Hydrops fetalis associated with homozygosity for $\mathrm{Hb}$ Adana [alpha59(E8)Gly-->Asp (alpha2)]. Hemoglobin 34: 394-401.

12. Duckett JW (1996) Hypospadias. In: Gillenwater JY, Grayhack JT, Howards SS, Duckett JW (eds): Adult and pediatric urology. 3rd edn. Mosby Year Book, St. Louis: 2550.

13. Fredell L, Lichtenstein P, Pedersen NL, Svensson J, Nordenskjöld A (1998) Hypospadias is related to birth weight in discordant monozygotic twins. J Urol 160: 2197-2199.

14. Morgan EA, Nguyen SB, Scott V, Stadler HS (2003) Loss of Bmp7 and Fgf8 signaling in Hoxa13-mutant mice causes hypospadia. Development 130: 3095-3109.

15. Mortlock DP, Innis JW (1997) Mutation of HOXA13 in hand-footgenital syndrome. Nat Genet 15: 179-180.

16. Utsch B, Kaya A, Ozburun A, Lentze MJ, Albers N, et al. (2003) Exclusion of WTAP and HOXA13 as candidate genes for isolated hypospadias. Scand J Urol Nephrol 37: 498-501.

17. van der Zanden LF, van Rooij IA, Feitz WF, Knight J, Donders AR, et al. (2011) Common variants in DGKK are strongly associated with risk of hypospadias. Nat Genet 43: 48-50.

18. Carmichael SL, Mohammed N, Ma C, Iovannisci D, Choudhry S, et al. (2013) Diacylglycerol kinase $\mathrm{K}$ variants impact hypospadias in a California study population. J Urol 189: 305-311.

19. Ma Q, Tang $\mathrm{Y}$, Lin $\mathrm{H}, \mathrm{Xu} \mathrm{M}, \mathrm{Xu}$ G, et al. (2014) DGKK Variants and hypospadias in Han Chinese: association and meta-analysis. BJU Int .

20. Dame C, Albers N, Bartmann P (1999) Candidate gene involved in genital ontogeny in chromosome region 16p13.3. Am J Med Genet 86: 302-303.

21. Utsch B, Albers N, Dame C, Bartmann P, Lentze MJ, et al. (2001) Homozygous alpha-thalassemia associated with hypospadias: SEA-type deletion does not affect expression of the -14 gene and loss of the straight 
Citation: Hassan S, Ahmad R, Hamid FSA, Aziz NA, Omar SL, et al. (2015) Transfusion Dependent Homozygous a-Thalassemia in Patients Associated with Hypospadias in Three Survivors. J Blood Disorders Transf 6: 248. doi:10.4172/2155-9864.1000248

Page 4 of 4

theta1-globin gene on $16 \mathrm{p} 13.3$ is compensated by its duplicate straight theta2 on chromosome 10. Am J Med Genet 101: 286-287.

22. Beaudry MA, Ferguson DJ, Pearse K, Yanofsky RA, Rubin EM, et al. (1986) Survival of a hydropic infant with homozygous alphathalassemia-1. J Pediatr 108: 713-716.

23. Dame C, Albers N, Hasan C, Bode U, Eigel A, et al. (1999) Homozygous alpha-thalassaemia and hypospadias--common aetiology or incidental association? Long-term survival of Hb Bart's hydrops syndrome leads to new aspects for counselling of alpha-thalassaemic traits. Eur J Pediatr 158: 217-220.

24. Fung TY, Kin LT, Kong LC, Keung LC (1999) Homozygous alphathalassemia associated with hypospadias in three survivors. Am J Med Genet 82: 225-227.

25. Ng YP, Joseph R, Biswas A (2008) Homozygous alpha-thalassemia in a growth retarded, non-hydropic premature newborn. J Perinatol 28: 158-159.
26. Cürük MA, Dimovski AJ, Baysal E, Gu LH, Kutlar F, et al. (1993) Hb Adana or alpha 2(59)(E8)Gly-->Asp beta 2, a severely unstable alpha 1globin variant, observed in combination with the -(alpha) $20.5 \mathrm{~Kb}$ alphathal-1 deletion in two Turkish patients. Am J Hematol 44: 270-275.

27. Traeger-Synodinos J, Metaxotou-Mavrommati A, Karagiorga M, Vrettou C, Papassotiriou I, et al. (1999) Interaction of an alpha(+)-thalassemia deletion with either a highly unstable alpha-globin variant (alpha2, codon 59, GGC-->GAC) or a nondeletional alpha-thalassemia mutation (AATAAA-->AATAAG): comparison of phenotypes illustrating "dominant" alpha-thalassemia. Hemoglobin 23: 325-337.

28. Utsch B, Albers N, Ludwig M (2004) Genetic and molecular aspects of hypospadias. Eur J Pediatr Surg 14: 297-302. 